\title{
Community of Practice or Practice Communities: Online Teacher Development
}

\author{
Adam Unwin \\ UCL Institute of Education, United Kingdom
}

\begin{abstract}
This paper draws on research from a larger project that concerned new teachers studying the Master of Teaching (MTeach). The research was interested in how teacher's participation in the online discussions (ODs) contributed to feelings of community and how this helped them develop and understand better their practice. It was apparent that participants felt that elements of community developed during the MTeach and that the ODs helped facilitate and sustain this community. This is something that sometimes contrasted with their experiences in school or was an additional support network for them. The value of these communities manifested itself in participants feeling less isolated, feeling safe, being able to honestly share and compare experiences in a non-judgmental way, feeling trust and being empowered and more confident about their teaching strategies. The ODs enabled a practitioner focus where participants could share information and experiences and seek advice.

This centered on what was happening at school, in their department, in their classroom, with groups and with individual students. Often this involved discussing relatively short term issues and ideas but there was clear evidence of longer term strategies starting to develop and be considered important. These practical issues were not only about their classes and teaching but also about wider early professional development (EPD) matters such as support and power relations. Findings are that the ODs provided a sense of community, with an underlying practitioner focus that developed their criticality. That these gains were the result of careful pedagogic design that underpinned the ODs.
\end{abstract}

\section{Introduction}

The Master of Teaching (MTeach) course was designed in 2000 to focus on the development of teachers in the challenging early phase of their teaching careers [4]. These were made up from teachers from different schools, phases (primary and secondary) and subjects. The context is important: these are new teachers are vulnerable to heavy workloads and tend to be time poor. They have views on pedagogy and they are situated in schools with day to day experiences and concerns which they need to draw on, share and make sense of if their development is to be meaningful. The course is 'mixed mode' in the sense that both face to face (f2f) sessions and online components are used. There is a tendency to assume educational benefits when introducing technology to the learning process without taking a critical and analytical perspective to what is actually happening and why this might improve (or not) the learning process [15] [16]. Laurillard neatly summarizes this as 'How do we ensure that pedagogy exploits the technology, and not vice versa?' [10].

Most Higher Education (HE) courses include online elements, yet student online course experiences are variable. Recent studies for example a review by Cole [2] have found that convenience is often the reason given for satisfaction, and lack of interaction the most common reason for dissatisfaction. Further research by Lorenzo [12] regarding student satisfaction with online learning points to wider factors that act as barriers to a positive learning experience, for example, technical, access and design issues that can affect learner motivation and engagement.

This paper draws on an in-depth research project concerning student experience of participating in the MTeach and in particular the online elements. The aim here is to focus on two important phenomena that emanate from this work that of community and of practice. This resonates with two pedagogic ideas that underpin what the MTeach is trying to achieve and the way it operates. First, there is a clear focus on the participants' own teaching, their students, their classrooms and their schools. It is a starting point for them to engage critically with practical and theoretical educational issues by trying to make sense of their situated practice [12]. Secondly, it is about participants communicating and reflecting on their own and each other's practice. It is believed that this sharing and explaining of their experiences and ideas will not only deepen understanding of the complexities at play in teaching but also encourage 
reflexivity and analysis. What is of interest is whether this communication fosters the development of a 'community of inquiry' [6] [7] within the online groups.

'...a community where individual experiences and ideas are recognized and discussed in light of societal knowledge, norms and values' [6]

\section{Data and Analysis}

The data gathered for this research was from a sample from five successive cohorts of new teachers $(n=22)$. This included their accounts of participation in the ODs, written towards the end of the first year of teaching and interviews conducted with a selection of these teachers at a later stage in their career. Using this data enabled the research 'to gain access to their accounts and articulations' [13]. The research was guided by the main question: how have the ODs facilitated new teacher development within the context of the MTeach? The theoretical perspective adopted for this research was interpretive with a methodological approach that used qualitative data. Coding utilized qualitative data analysis software (NVivo) and analysis was assisted via 'thick descriptions' [3].

\section{Community and Practice}

This paper is going to draw on Lave and Wenger's [11] work on situated learning and Wenger's [18] communities of practice (CoP) to help explain aspects of what appeared to happen on the MTeach. Mayes and de Freitas foreground 'the situative perspective' [14] suggesting the potential of online communities which also resonates strongly with the pedagogic design behind the ODs. The term 'communities of practice' was originally formulated by Lave and Wenger [11]. The authors' original theory was developed through an analysis of ethnographic studies on how apprentices learn in different settings. The concept of 'legitimate peripheral participation' is used to characterize learning, broadening the traditional view of apprenticeship from a master/student relationship 'to one of changing participation and identity transformation in a community of practice' [18]. Wenger has subsequently worked on developing conceptual thinking about how $\mathrm{CoP}$ operate and can be applied in a variety of contexts. Central to the concept of a CoP is that people come together to carry out various activities whether this be in work, education or wider life environments. Wenger argues that these groups are characterized by three dimensions (see figure $\mathrm{x}$ below). Firstly that there is joint enterprise meaning that members of the group have some sort of common endeavor. Secondly that there is mutual engagement where people interact, develop and share practices. And thirdly there is a shared repertoire where the group has developed common resources of language, styles and routines for expressing their identity as part of the group.

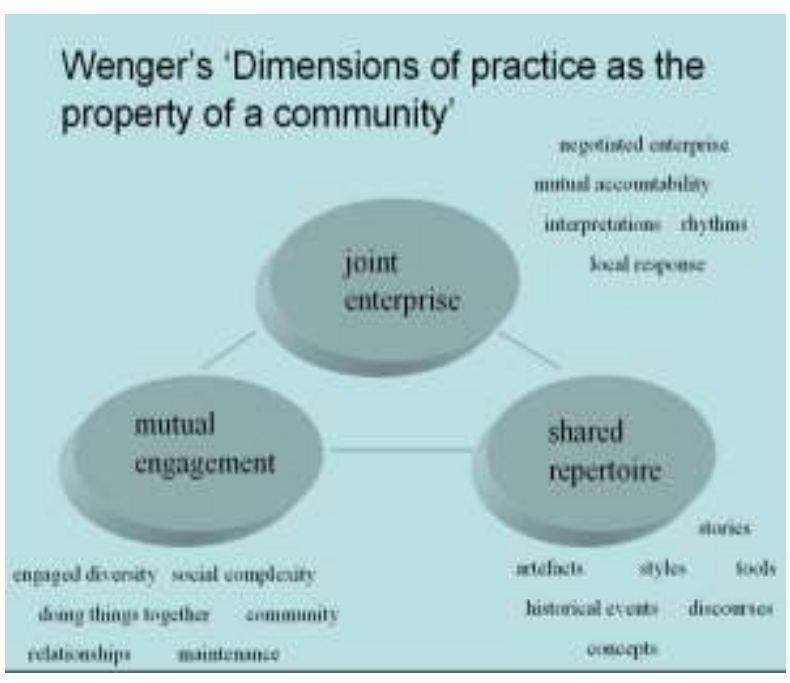

Figure 1. Wenger's Dimensions of practice as the property of a community [18]

These dimensions are core to the formulation of a CoP and the strength of its knowledge construction potential. The educational thinking behind the MTeach and the way it functions in practice offer strong parallels with these key dimensions of CoP. Students (all teachers) communicate and interact with each other using a shared and developing repertoire of educational language and understanding in what is the common endeavor of both progressing with their studies but also making sense of their professional (teaching) lives. Wenger suggests situated learning occurs when there is engagement within a CoP and key to this for learning is the requirement or presence of social interaction and a location in practice. He uses the concepts of participation and reification to analyze, unpick and develop the importance of the need for social and practice within a CoP. The concept of participation Wenger explains is used as it would be everyday language. 'Participation refers to a process of taking part and also to the relations with others that reflect this process. It suggests both action and connection.' [18] Reification Wenger acknowledges as less in common usage. He goes on to explain how reification is central to any practice and that although the dictionary definition of making something real or concrete is important the term in this context includes a wider range of processes (e.g. designing, representing, describing, using, reusing, perceiving, interpreting) that occur within a CoP. These key features of Wenger's thinking resonate strongly within the design and practice of how the MTeach ODs work. The ODs are designed to encourage participation within a context which is more than sharing and exchanging views and experiences on 
practice (although this is important), students can and do utilize a wider range of reification processes in a similar vein to those emphasized by Wenger.

The next section gives some samples from the data collected in this project. These are extracts where different teachers $(T)$ explain what participating in the ODs meant for them experience wise and for their professional development. They have been selected as they resonate with aspects of the community and practice focus of this paper. The samples are presented firstly with a community emphasis followed by a practice emphasis.

\subsection{Community}

Teaching can feel isolating when you are stressed, and it can really help to hear how others are doing and that some of the issues you face are also faced by others. I believe the value of teachers sharing their experiences from different subjects and schools is an area of underestimated worth. It has been useful to read about activities or research that other teachers are doing with their students. (T1)

The really positive aspect of the online discussion was having a confidential and supportive environment, with which to discuss problems or issues being faced at school. In addition, I welcomed the opportunity to work collaboratively, as the discussions enabled reflection on classroom practice. (T2)

The online discussions allow one to voice concerns in an environment where no one will judge, as they are all going through the same difficulties. When things are going right, it is helpful to share your views with other people, as they can tell you their views and, in helping them, one feels more confident in themselves. (T3)

XYZ's comments made me feel part of the online community and it felt good being able to share my ideas and that other people having success with the same techniques I had used, even though we teach completely different age ranges. (T4)

During our online discussion...... the task demonstrated powerfully the benefits of the MTeach "community of practice" (Banks, Leach \& Moon, 1999), which not only gives participants access to a wide range of theoretical and intellectual experience, but also to real practical support. (T5)

...many of the proposals covered areas I feel could benefit my professional development- and formative in the sense that I learnt more about to how evaluate my teaching from other participants. (T6)

... it was really good to have that contact with other NQTs, who would have these discussions about what the research says, and then there would always be - but don't you find that actually in the classroom this happens, and this happens? And that readymade community was really good, because in my school there were a couple of other NQTs, but you didn't actually have that forum, have that structured place to kind of discuss things. (T7)

This conversation gave me the confidence to include group work (rather than pair work) in my observed lesson... I found this discussion extremely rewarding. As we were building on understandings of meta-cognition and collaborative learning constructed in previous conversations, I think that the interrelation of such concepts became clearer. I certainly feel more confident in my understanding of these issues than at the beginning of the year. (T8)

I gained confidence from postings by other MTeach colleagues and realised that many of us were experiencing similar concerns. I know that as an inexperienced teacher my 'pedagogical knowledge' is constantly developing. (T9)

I think the way that it helped was it gave you reassurance that experiences that you were encountering were in other schools. And within the school environment you can feel quite isolated, in a small department of perhaps two or three other members of staff, and it's not always possible to have continuous conversations on a particular topic. (T10)

So it didn't matter if you were discussing something that you found difficult, where in the school surroundings I felt that I was being judged and I shouldn't really show that I had weaknesses. (T11)

\subsection{Practice}

This was the opposition on which my reflective practice fixated: between my struggle to manage behaviour, and my determination to put all my thought into devising collaborative tasks and resources that connected students with their curriculum. ABC's writing suggested a similar tension; his initial task, however, focused entirely on responses to bad behaviour. His phrasing cast a happier light on my behaviour-learning dilemma: my concentration on planning rather than behaviour wasn't a cop out; it was 'proactive'. (T12)

Since this first online discussion, I have developed my use of group work and now incorporate role play into lessons; this is a direct result of this first discussion and the background readings. (T13)

What proved most beneficial from this discussion was the change of focus it gave me when considering classroom management. Before the discussion I was constantly looking for sanctions and to punish bad behaviour. After the discussion I realized that I had a large majority of well-behaved and motivated students and that I needed to reward them. (T14)

I also noticed that my relationship with my students changed from constantly focusing on their negative 
behaviour to a more positive relationship where I was praising them more regularly. I had also become more proactive and began to anticipate difficult behaviour and have systems in place to prevent misbehaviour from occurring. (T15)

Overall, the online discussions have been a valuable tool. They have directly aided my teaching, thanks to a lengthy series of original and insightful ideas that are specifically tailored to the classroom. More importantly, though, in the long term they have made me confident about seeking advice, about trying new things, about believing that there is never any need to abandon attempts to teach higher order skills. (T16)

The last online discussion improved my understanding of pedagogy and the key factors that should be considered. My focus at the beginning of the year was on what and how I was teaching. I believe my focus has changed during the course of these online discussions. My focus is generally upon the learning taking place rather than my teaching. I have become aware of the different variables as described by Kyriacou. I now consider these variables when planning, teaching and evaluating lessons. (T17)

... it was one that really stuck with me, it really helped me, because it was the first time that, people had given me advice about this year ten class, do this, do that, and little things to keep them on task, but it was the first time that something had really worked, and worked to the level that I wanted it to work, it wasn't just a trick that meant they were silent for ten minutes. I could actually see that things were changing and moving on. (T18)

It is clear that features one would expect to see as a community starts to evolve are happening here. There is trust, support, shared identity (being part of something) and empathy (understanding each other's situations). This qualitative data points to what is special for new teachers on the MTeach is that they have a space separate from work where they can raise issues of concern and interest and this is in a community of equals or peers. For example, they can question school policy or micro-community practice without feeling vulnerable, judged and compromised. They can also be honest and explicit about their progress, what they fear, what has gone wrong, what has gone well, what they find frustrating and other challenges. In the ODs they are 'listened to' and receive feedback about issues specific to them and their context which provides a supportive community with a semi-cathartic role. This community forming process is underpinned by the way the ODs are designed, where participants initially present to the whole group classroom practice issues that are of contemporary interest to them. They subsequently receive feedback from others with threads of discussion often developing. What makes this process more empowering (and perhaps less threatening) is that the online group has the added dimension of an inter-subject and inter-phase collegiality, with participants benefiting from understanding beyond their school or subject microcommunity. By developing their criticality in this way at this early stage of a teaching career, teacher professional judgement is allowed and valued. What happens is participants' critical engagement with practice becomes integrated into their school contexts and communities. Participants explained how the development they gained via the MTeach was different from their experiences at school. They were often complimentary about aspects of school support, feeling that the MTeach supplemented this and gave them wider perspectives: neatly summarized by one participant as the 'why' not the 'how'.

It is apparent this MTeach online community encourages the development of Wenger's 'dimensions of practice'. There is a strong presence of 'shared repertoire' and 'mutual engagement'. Key elements of 'joint enterprise' exist in a more embryonic form. For example, 'interpretations' and 'mutual accountability' are clearly present whereas 'negotiated enterprise' is less developed. Interestingly the participation is rich in reification. Arguably the pedagogic design aims to foreground the situated experiences of teachers. By making the sharing of experiences key to the ODs reification occurs. The processes of making their teaching situations real to others will require for example representing, describing, using, reusing, perceiving and interpreting. It was important that participants could raise and discuss practical teaching strategies and problems in an open and honest way. The combination of the use of their own experiences along with readings made them think about their situations in a less restricted way. The multiplicity of practical suggestions and ideas allowed participants to experiment within their own context on their own terms and move from reactive to proactive strategies. As with the development of community this centrality of thinking about practice incubated aspects of confidence building and empowerment.

Yandell [19] when discussing student teachers' school experiences also draws on Lave and Wenger's [12] work explaining how peripheral participation and overlapping communities of practice can be difficult but provide a 'privileged vantage point'. 'These are not necessarily comfortable relations, and there are frequently tensions and contradictions both within and between intersecting communities of practice.' [19] He goes on to say '...peripheral participation can also be a privileged vantage point, a position from which to make sense of the hurlyburly...' [19]

This resonates with what is happening for the MTeach participants, they are new teachers and they are subject to competing pressures and expectations 
within their school communities (where they are novices). They also are undertaking the MTeach and becoming part of that community, which is facilitated by the ODs (between peers). The participation within this overlapping community of practice gives them both support and the confidence to look at what is happening in their schools and classes in alternative and critical ways. Their participation in the MTeach strengthens their school roles, giving them the self-assurance to suggest and introduce new ideas; contributions which were often recognized as valuable and acted upon. Thus, the community formation and practitioner focus are intrinsic parts (and are outcomes) of the MTeach ODs that gives credibility to the new teachers in their school communities.

\section{The Role of Technology}

There are a number of ways technology assists what happens on the MTeach. For example, participants have flexibility to access materials and work on activities from a distance when it suits them (within certain structures and timelines). The technologies used influence the pedagogic design, for instance it was decided to use an asynchronous discussion forum for the ODs. These asynchronous discussions work within the overall aims of what the ODs aim to achieve: allowing participants to utilize their own and each other's professional teaching experiences as a critical 'way in' to the topics and issues covered by the course. It is the course team that makes decisions as to how to use them (timings, structures, requirements) and these are pedagogic decisions. This research has confirmed the importance of not being constrained or pushed in a particular direction by the technologies. Rather, there is a need to develop approaches that utilize the affordances technology offers to achieve the desired pedagogy.

More specifically with teachers in mind Fisher et al [5] explain how teacher learning is complex, multifaceted and 'resistant to standardization' but there are 'affordances' digital technologies can offer to enhance teacher learning. They provide a framework for categorizing and describing these concepts and activities.

The MTeach uses technology to facilitate the ODs by providing a forum (the online tutor group) and various digital artefacts and resources. What is evident from the research is that the ODs achieve to varying degrees purposeful activities from all clusters. It is the community and communication cluster that features strongly and this facilitates the development of activities in the other clusters. For example, the way the ODs are set up requires teachers to participate within a community, to share and exchange information, which in turn leads to activities such as 'adapting and developing ideas' and 'writing, composing and presenting' from the other clusters.

Table 1. Clusters of purposeful activity with digital technologies [5]

\begin{tabular}{|l|l|}
\hline $\begin{array}{l}\text { Knowledge } \\
\text { building }\end{array}$ & $\begin{array}{l}\text { - adapting and developing ideas } \\
\text { - modelling } \\
\text {-representing understanding in } \\
\text { multimodal and dynamic ways }\end{array}$ \\
\hline $\begin{array}{l}\text { Distributed } \\
\text { cognition }\end{array}$ & $\begin{array}{l}\text { - accessing resources } \\
\text { - finding things out } \\
\bullet \text { writing, composing and } \\
\text { presenting with mediating } \\
\text { artefacts and tools }\end{array}$ \\
\hline $\begin{array}{l}\text { Community and } \\
\text { communication }\end{array}$ & $\begin{array}{l}\text {-exchanging and sharing } \\
\text { communication } \\
\bullet \text { extending the context of activity } \\
\bullet \text { extending the participating } \\
\text { community at local and global } \\
\text { levels }\end{array}$ \\
\hline Engagement & $\begin{array}{l}\text { exploring and playing } \\
\bullet \text { acknowledging risk and } \\
\text { uncertainty } \\
\bullet \text { working with different } \\
\text { dimensions of interactivity } \\
- \text { responding to immediacy }\end{array}$ \\
\hline
\end{tabular}

Fisher et al [5] suggest that professional development will benefit by 'designing in' (author words) community and communication. 'The community and communication affordances are exploited as teachers reflect upon their practice within a wider community. They can use communication tools to engage in reflective analysis of materials and experiences with colleagues and mentors, and such opportunities for reflection, both on general practice and the use of ICT in their teaching, need to be built into and prioritized in the design of professional development schemes and innovations.' [5]

This concurs with what this research has found on the MTeach. The ODs use the technology to allow participants to share their reflections and experiences. The pedagogic design behind the OD considers carefully where these teachers are situated and the pressures they are under. Providing communication tools in itself is not enough; the communication expectations need to be realistic. Early in their paper Fisher et al encapsulate what they feel is needed for teacher learning to be successful. 'Teachers learn and develop their professional knowledge best when the aims and purpose of activities are relevant and authentic to their own lives; when they can use a variety of tools to help them realize and express their goals; and when they are in relationship with others in the wider community which shares rules and ways of working' [6]. Again, this resonates strongly with the pedagogic 
design that enabled such processes within the MTeach ODs.

How far what happens in the ODs represents collaborative knowledge construction is more difficult to assess. To gain a sense of what is happening it is useful to revisit ideas and concepts from literature that concern learning within online forums and are not specifically about teacher learning. The community aspect of the ODs certainly facilitates 'the social dimension of learning (the discussion of theory, the exchange of ideas, negotiating meaning)' [10] and there is evidence of 'the practice of discussion and argument in order to develop theory' [10]. It is important to note that theory development is not a specific aim of the ODs as they are about gaining a critical understanding of practice, seeing the connections between knowledge, understanding, theory and practice. Rather than participants trying to achieve a collaborative outcome the ODs are designed to be a collaborative process where 'learner participation leads to multiple perspectives on issues, a divergence of ideas, and positions that students must sort through to find meaning'[8]. The nature of this joint process reminds us that what is happening within the ODs is akin with the concept of a 'community of inquiry' [6] [7]. This enquiry is encouraged by each OD having an overall focus to which participants bring their own views and situated accounts of professional practice. The ODs could be described as having a formative role in knowledge construction where participants are in 'a community where individual experiences and ideas are recognized and discussed' [6]. This formative role appears to offer support and direction for participants to follow both in developing their practice and their understanding (theoretical or otherwise) of what is happening within their own and wider contexts. Thus ODs construct a collaborative process but it is the individual learner who must grasp its meaning or offer an improved understanding.' [6]

\section{Conclusion}

What is important in the way the ODs operate is that they endorse an engagement with the 'complexity of the classroom' [17] and in doing so question simplistic solutions or strategies. They foster an enquiry approach, which by its nature is forward thinking and moves away from the immediacy of presentism. This future orientation means strategies become longer term, more holistic and grounded in why things happen as opposed to adopting approaches which are judgmental, formulaic and over focused on the negative. This forward thinking and enquiry although concerned with participants' own contexts, are assisted by the community and by the artefacts that make up the online activities. These have an important formative role and demand engagement with theoretical concepts and wider perspectives that go beyond their subject, phase or school context. The way the ODs are designed, the way they operate, the multi-faceted contexts of participants and the actual outcomes (the discussions) are all important in making them work in a way that counters short term reactive approaches [9]. This combination of factors encourage a questioning a 'reflective skepticism' towards new initiatives, policy and best practice models rather than a passive acceptance. They were experiencing a 'pedagogy of discomfort' [1] where their educational assumptions were challenged by themselves and each other. There is a sense that their evolving identities as teachers were linked and shaped by the MTeach and the ODs.

This paper is titled 'Community of Practice or Practice Communities: online Teacher Development'. Participants certainly valued the community made up of similar (all new) but different (schools, phases and subjects) teachers, where they felt they could be honest and open. The practitioner focus was important with the starting point for the ODs being their own classrooms and issues of concern and interest to them. This practitioner focuses along with the structure and timing of the ODs made it manageable in the very busy first year of teaching. Wenger explains how his use of the term reification is more than the dictionary definition of making something real or concrete. It has a relationship with participation that includes a range of processes (e.g. representing, describing, using, reusing, perceiving, and interpreting) which become central to the community of practice. This work recognizes that the situating of the online tasks in professional practice leads to reification. The participation required and reification that developed are intrinsically linked. The role community plays is important in enabling this process and functions at various levels in what are overlapping communities of practice. The teachers' experiences in these multiple communities of practice are shared and feed off each other to enrich their critical understanding of educational practice issues at an early career stage. One would argue thus an initial practice community over the space of a teaching year develops into a rich CoP.

\section{References}

[1] Boler, M. Feeling Power: Emotions and Education. Routledge, New York and London, 1999.

[2] Cole $M$ et al Online Instruction, E-Learning, and Student Satisfaction, The International Review of Research in Open and Distributed Learning. Vol 15, No 6 2014

[3] Creswell, J. and Miller, D. 'Determining Validity in Qualitative Inquiry Getting Good Qualitative Data to 
Improve Educational Practice'. Theory into Practice 39 (3), 2000, pp.124-130.

[4] Daly, C., Pachler, N. and Lambert, D. 'Teacher learning: towards a professional academy'. Teaching in Higher Education, 2004 vol 9 (1).

[5] Fisher, Higgins and Loveless, 2006 Fisher, T., Higgins, C. and Loveless, A. (2006). Teachers learning with Digital Technologies: A review of research and projects: Futurelab.

[6] Garrison, D. and Anderson, T. E-Learning in the 21st Century: A Framework for Research and Practice. RoutledgeFalmer, London, 2003.

[7] Garrison, D., Anderson, T. and Archer, W. 'Critical thinking, cognitive presence and computer conferencing in distance education'. American Journal of Distance Education, 15 (1), 2001, pp.7-23.

[8] Harasim, L. (2000). 'Shift happens. Online education as a new paradigm in learning'. The Internet and Higher Education, 3 (1), 41-61.

[9] Hargreaves, A and Shirley, D 'The Persistence of Presentism' Teachers College Record Volume 111 Number 11, 2009, p. 2505-2534

[10] Laurillard, D. (2009). 'The pedagogical challenges to collaborative technologies'. Journal International Journal of Computer-Supported Collaborative Learning 4 (1), 520.

[11] Lave, J. and Wenger, E. Situated Learning: Legitimate Peripheral Participation, Cambridge University Press, Cambridge, 1991.

[12] Lorenzo, G A Research Review about Online Learning: Are Students Satisfied? Why do Some Succeed and Others Fail? What Contributes to Higher Retention Rates and Positive Learning Outcomes? Internet Learning: Vol. 1: Issue. 1. 2012

[13] Mason, J. Qualitative Researching, Sage, London, 1996.

[14] Mayes, T. and de Freitas, S, JISC e-Learning Models Desk Study Stage 2: Review of e-learning theories, frameworks and models. JISC, 2004

[15] Mishra, P. and Koehler, M. J. 'Technological Pedagogical Content Knowledge: A Framework for Teacher Knowledge'. Teachers College Record, 108 (6), 1017-1054, 2006

[16] Oliver, M. 'Looking Backwards, Looking Forwards: An overview, Some Conclusions and an Agenda'. In J. Seale (Ed.), Learning technology in transition : from individual enthusiasm to institutional implementation ( $\mathrm{pp}$. 166). Lisse ; Abingdon: Swets and Zeitlinger, 2003.

[17] Quarshie, R. Classroom Interactions: The complexity of the classroom. Master of Teaching (MTeach) VLE: Institute of Education, 2015.
[18] Wenger, E. 'Communities of practice: learning, meaning and identity'. Cambridge: Cambridge University Press, 1998.

[19] Yandell, J. 'Sites of Learning', Critical practice in teacher education : a study of professional learning (pp. 15-28). London: Institute of Education University of London, 2010. 